\title{
Torsten Löwhagen, M.D., F.I.A.C.
}

\section{9-1999}

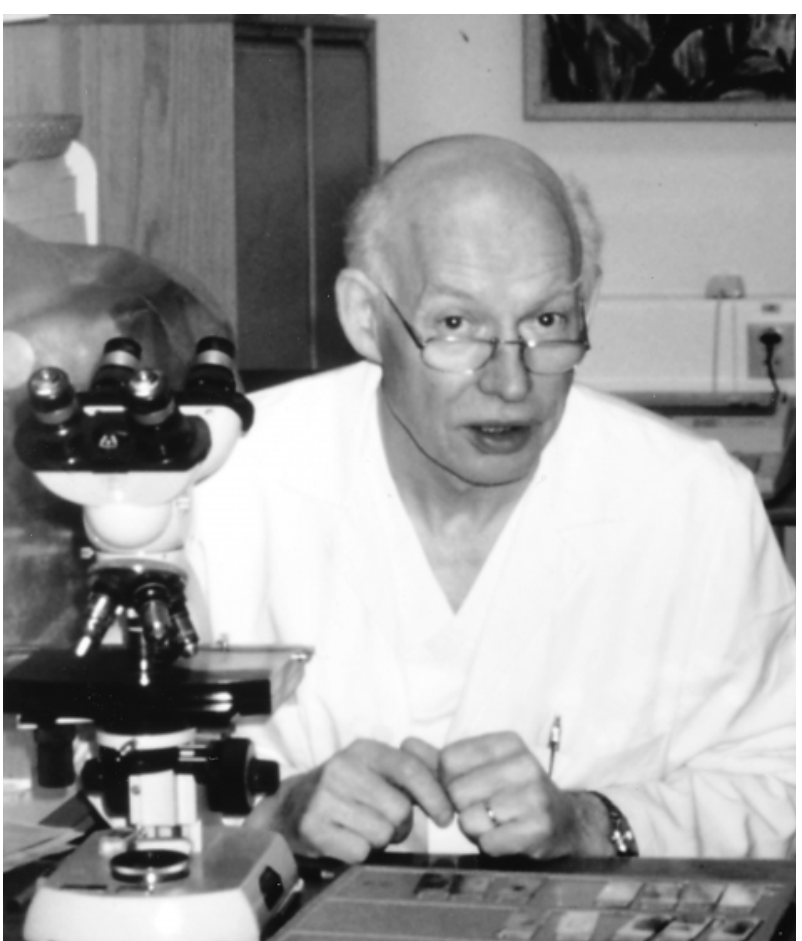

Torsten Löwhagen, M.D., F.I.A.C.

During sleep early on the morning of December 12, 1999, Dr. Torsten Löwhagen lapsed into a coma. He died later in the day at Karolinska Hospital, where he had worked most of his adult life. His family and friends were shocked because he was vigorously engaged in a busy schedule of activities up to the time of his death.

In 1993, Dr. Löwhagen received an honorary medical doctorate (equivalent to a Ph.D.) from the Karolinska Institute marking his contributions as a teacher, physician and scholar. He published over 50 articles on aspiration cytology in scientific journals and coauthored monographs and textbooks on this topic. He lectured and served as a visiting professor widely throughout Europe, Asia and the Americas. In 1995, he received the 35th Papanicolaou Award from the American Society of Cytopathology for his contributions to cytology, joining a list of pioneers and titans in the field. His acceptance speech before the annual meeting of the society, delivered in his easy, humorous style, recounted the development of aspiration cytology at Karolinska Hospital and graciously acknowledged the work of his colleagues, Drs. Sixten Franzén and Josef Zajicek.

Franzén, a hematologist, began sampling palpable tumors at Karolinska in the late 1940s and provided several important technical innovations. Zajicek, a pathologist, systematically recorded and analyzed the results of aspiration biopsies at Karolinska and published his observations extensively. Löwhagen was a principal participant in the aspiration clinic from the mid-1970s through his retirement in the 1990s and during this period managed the fellowship program, training over 275 foreign physicians in the basics of aspiration biopsy and cytology.

This group of physicians adapted the Karolinska experience to their local practices, significantly contributing to the growth of aspiration biopsy through the 1990s. Those who trained with Dr. Löwhagen universally comment upon his patience and enthusiasm as a teacher, his empathy for patients, his decisiveness as a diagnostician and his generosity as a colleague and host. Many returned to Sweden for additional training, for collaborative studies or simply for spending more time with an extraordinary human being.

Dr. Löwhagen is survived by his wife, Dr. AnnaStina Löwhagen; their son, Johan; their daughter, Lotta; three grandchildren; and the joyful memories of those who knew and worked with him.

Jerry Waisman, M.D., M.I.A.C. 